\title{
Towards Democratic Models of Science: Exploring the Case of Scientific Pluralism.
}

\author{
Jeroen Van Bouwel \\ Ghent University, Belgium \\ Jeroen.VanBouwel@UGent.be
}

\begin{abstract}
Scientific pluralism, a normative endorsement of the plurality or multiplicity of research approaches in science, has recently been advocated by several philosophers (e.g., Kellert et al. 2006, Kitcher 2001, Longino 2013, Mitchell 2009, and Chang 2010). Comparing these accounts of scientific pluralism, one will encounter quite some variation. We want to clarify the different interpretations of scientific pluralism by showing how they incarnate different models of democracy, stipulating the desired interaction among the plurality of research approaches in different ways.

Furthermore, the example of scientific pluralism is used to advocate the application of democratic theory to philosophy of science problems in general. Drawing on the parallels between models of science and models of democracy, we can articulate how the plurality of research approaches in science should interact within a democratic framework as well as how to cultivate multiple research approaches in the epistemically most productive way possible. This will not only improve our understanding of scientific plurality, but it can also help us stipulating how different research approaches should interact to constitute the most objective account possible or how the ideal of scientific consensus has to be understood. Ultimately, developing democratic models of science bears on the question of how deeply science and democracy are entwined.
\end{abstract}

\section{Introduction.}

The relations between science and democracy are many. In this paper, I want to demonstrate how democratic theories or models of democracy can help us addressing questions in philosophy of science. I do so by way of an example, focusing on the case of (philosophical understandings of) scientific pluralism. In the first section, the philosophical debate about scientific pluralism is introduced. Section 2 discusses three possible ways of making progress in this debate, i.e., (a) by philosophical discussion, (b) by analyzing scientific practice and (c) by using democratic theory. The third way is exemplified in Section 3, where Chantal Mouffe's account of agonistic pluralism is presented and applied to the different versions of scientific pluralism in philosophy of science. The fruitfulness of using models of democracy is spelled out in Section 4, considering both the lessons for the philosophical debate and the consequences on the level of scientific practice. ${ }^{1}$ Furthermore, I show in Section 5 that using models of democracy is not only useful in the case of scientific pluralism; other central problems in philosophy of science, like scientific objectivity, might benefit from it too. Ultimately, developing democratic theories of science will teach us how deeply science and democracy are interwoven and how social-epistemic processes can be adjusted.

\footnotetext{
${ }^{1}$ When I talk about science in this paper, I also include the behavioral and social sciences.
} 


\section{Introducing scientific pluralism.}

Studying the actual practice of science, we come across many instances in which scientists analyzing one and the same phenomenon, for instance, aggressive behavior, provide us with very different explanations of the phenomenon using different (seemingly) irreconcilable approaches, i.e. behavioral genetics (molecular or quantitative), social-environmental approaches (behavioral dispositions of socialization patterns, familial environments, and/or parental attitudes and interactions with their children), neurobiology (physiology and anatomy - the neural substrate of behavior) or the developmental systems approach (cf. Longino 2006, 2013). One finds similar situations in biology, for instance, the alternative models of predator-prey dynamics in population biology, in economics, think about the explanations given for the financial crisis, in physics, e.g., in quantum dynamics (cf. Dickson 2006), or, in chemistry (cf. Chang 2012). This raises the question of how to deal with this multiplicity of explanations, theories, models, research approaches, classificatory schemes, knowledge systems, ... in science.

Scientific pluralists endorse this multiplicity and consider it to be beneficial - and this holds for various possible views about the aim of science. If the aim of science is taken to be Truth, the main argument for pluralism is based on the unpredictability of scientific development - since we do not know which line of inquiry will be ultimately successful, it makes sense to cultivate various lines. If the main aim of science is empirical adequacy or understanding, there are further arguments for pluralism because different systems of knowledge can contribute to the aim in different ways. If we regard science to have various aims simultaneously, then there are even further pluralist arguments (cf. Chang, 2010).

Thus, while earlier philosophers of science were mostly pondering over how to identify the best theory, method and/or approach in science presuming scientific monism, the pluralist philosophers consider the viability of the view that phenomena might require multiple accounts -as the serious study of actual scientific practice teaches them- and they advocate scientific pluralism. In a very general way, one could define this scientific pluralism as a normative endorsement of the multiplicity of knowledge systems theories, models or research approaches - in each area of science. It is contrasted with scientific monism that evaluates approaches on the basis of whether they can provide a single, comprehensive and complete account of phenomena. Rather than developing methods to select or justify the one best knowledge system or research approach, pluralist philosophers chew over how to deal with the multiplicity of knowledge systems; how they (should) interact, how this interaction can be made as productive as possible, what it requires from the scientist to operate in a pluralistic mode, how to choose a knowledge system to deal with a specific problem, etc.

However, hovering over the current literature on plurality in science, we can only conclude that the answers to these questions diverge a lot. To give you a hint of the variety of scientific "pluralisms", compare: "integrative pluralism" contrasted with "isolationist pluralism" (Mitchell 2009), "perspectival pluralism" (Giere 2006), "theoretical pluralism" (Longino 2006) and "ineliminable pluralism" (Longino 
2013), "modest pluralism" (Kitcher 2001), "foliated pluralism" (Ruphy 2011), "active normative epistemic pluralism" (Chang 2010) and "dynamic pluralism" (Wylie 2013). All of these contributions offer interesting insights and further our understanding of plurality, but they are often limited to a particular problem, irreconcilable when taken together, and, they do not provide us with the coherent and comprehensive account we would like to have. We might all be pluralists now, but we do differ.

Obviously, one can raise the question why philosophers should not be pluralists about scientific pluralism for the very same reasons philosophers recommend pluralism in science. My worry is that jumping to that conclusion might lead to a form of resignation as well as missing out on interesting and helpful insights concerning scientific pluralism. I think there is a lot to gain by systematically studying and comparing the strengths and weaknesses of the respective versions of scientific pluralism, e.g. which aims they serve, which questions or problems they tackle best, etc. Even if one wants to be a pluralist about pluralism, developing a framework, or some tool or basis for comparing the different versions of scientific pluralism, will help us to clarify what goals can be reached most adequately by which version of pluralism. And, maybe, one version of scientific pluralism might turn out to be superior anyway.

So, if we want to make progress on understanding plurality in science, an analytical clarification and comparison of the different interpretations of scientific pluralism as well as their ideas about how interaction between different research approaches can be made as productive as possible, are indispensable. In the next section, I discuss three possible ways of accomplishing this task: (1) compare and evaluate the philosophical literature, (2) analyze scientific practice, and, (3) apply models of democracy. Let it be clear that I consider these approaches to be cumulative, rather than mutually exclusive; I distinguish the three approaches to make clear what can be added to (1) the traditional philosophy of science approach. ${ }^{2}$

\section{Making scientific pluralism explicit: possible approaches.}

\section{a. Discussing philosophy of science literature.}

Consulting the philosophical literature on scientific pluralism, we do find insightful debates and comparisons between different versions of pluralism. One classic is the debate between Helen Longino and Philip Kitcher in Philosophy of Science (2002). Debating with Longino, Kitcher (2002b) sums up four claims of his version of scientific pluralism: "(1) there are many different systems of representation for scientific use in understanding nature; (2) there is no coherent ideal of a complete account of nature; (3) the representations that conform to nature (the true statements, the accurate maps, the models that fit parts of the world in various respects to various degrees) are jointly consistent; (4) at any stage in the

\footnotetext{
${ }^{2}$ Of course, the philosophical literature does itself analyze scientific practice, but traditionally much of that literature engages with the same simplified examples. That is why I want to emphasize the analysis of actual scientific practice as a second approach (2). All three approaches taken together might create an intervention in the philosophical literature as such - and thus become part of approach (1).
} 
history of the sciences, it's likely that the representations accepted are not all consistent." (Kitcher 2002b: 570-71)

Longino characterizes Kitcher's pluralism as modest. Kitcher does not presume monism; he allows different systems of representation, representing nature in a way that lives up to our interests, and he is cognizant of the incompleteness of these representations. But, according to Longino (2002b: 575): "No sense, however, can be made by Kitcher of my suggestion that equally successful representations may be irreconcilable or non-congruent in any non-redundant way. Hmm. I countenance pluralism because I countenance the possibility of different equally defensible background assumptions facilitating inferences to quite different and irreconcilable, even non-mutually-consistent, representations of what is pretheoretically identified as the same phenomenon." This could be the case, for instance, because: "Different equally defensible parsings of an ontological space can result in approach $B$ treating the causally significant factors of approach $A$ as undifferentiated portions of the environment of causally significant factors for B and vice versa." (Longino 2002b: 575)

Concerning Longino's understanding of plurality, it is important to mention that she does not exclude the possibility of monism (Longino 2002a: 75). She wants to avoid metaphysical prejudices and promote empirical study, i.e., identifying in which situations multiple models or explanations are required and studying how plurality in the particular sciences ought to be understood (cf. Kellert, Longino and Waters 2006). She describes her position as "a commitment to avoid reliance on monist assumptions in interpretation or evaluation coupled with an openness to the ineliminability of multiplicity in some scientific contexts. (...) the plurality in contemporary science provides evidence that there are kinds of situations produced by the interaction of factors each of which may be representable in a model or theory, but not all of which are representable in the same model or theory (...) A more complete representation of some phenomena in contemporary science does require multiple accounts, which cannot be integrated without loss of content." (Ibid: xiii-xiv) This is very different from Kitcher's approach; he presumes the different systems of representations to be jointly consistent, there is a way to integrate the plurality of approaches or accounts in a scientific discipline even though at "any stage in the history of the sciences, it's likely that the representations accepted are not all consistent" (Kitcher 2002b: 571). Kitcher's modest pluralism subscribes to the plurality present in contemporary science, but considers it to be resolvable (at least) in principle (cf., Kellert et al. 2006: xi). Where does this conviction of consistency stem from and how to justify it; what are the benefits of denying the possibility of non-reconcilability, non-monism?

Another form of modest pluralism is Sandra Mitchell's (2002, 2004, 2009). Her "integrative pluralism" articulates the need of integrating the respective findings concerning a phenomenon: "Developing models of single causal components, such as the effects of genetic variation, or of single-level interactions, such as the operation of selection on individuals (...) need to be integrated in order to understand what historical, proximal, and interactive processes generate the array of biological phenomena we observe. Both the ontology and the representation of complex systems recommend adopting a stance of integrative 
pluralism, not only in biology, but in general." (Mitchell 2004: 81). Mitchell acknowledges that the world is patchy, but she sees one theory or model explaining phenomena in one patch, and a different theory or model explaining similar phenomena in another patch, cf. "However complex, and however many contributing causes participated, there is only one causal history that, in fact, has generated a phenomenon to be explained." (Mitchell 2002: 66) Mitchell's understanding acknowledges a state of plurality of approaches, we might hold different theories for a number of reasons (the complexity of the world, our interests, the limitations or partiality of our explanatory strategies), but the understanding is that plural approaches can be (locally) 'integrated' after all. (Local) Integration is presumed to be possible and necessary in order to obtain satisfactory explanations: "The "levels of analysis" framework describes the territory of pluralistic investigations, but it is only by integration of the multiple levels and multiple causes, including attention to the diverse contexts in which they occur, that satisfactory explanations can be generated." (Mitchell and Dietrich 2006: S78) ${ }^{3}$

Although Kitcher (2002a: 556) writes on Longino that: "she wants to allow for the acceptability of representations that are "hard to reconcile" (...). Utter mystery descends at this point.", and suggests that several issues concerning Longino's understanding of scientific pluralism remain unclear, the debate between them at least helps us to distinguish two different versions of scientific pluralism, which I will label (ScPI 1) and (ScPI 2). Philip Kitcher's and Sandra Mitchell's versions of pluralism are instances of the first interpretation ( $S c P I$ 1) of pluralism. Helen Longino's interpretation illustrates the second, (ScPI 2). We can also distinguish a third version of scientific pluralism (SCPI 3) in the literature in which a plurality of knowledge approaches co-exists, but without there being any positive interaction among them (a picture of science in line with Thomas Kuhn's 1962). This co-existence without interaction might have several benefits, for instance: an insurance against unpredictability, covering different aspects of nature, multiple satisfaction of an aim, satisfaction of multiple aims (see Chang 2010 for the benefits of toleration without interaction).

(ScPI 1) Plurality and (local) integration/synthesis: there are many different systems of representation for scientific use in understanding the world, none of them complete, and jointly consistent (cf. Kitcher, Mitchell).

(ScPI 2) Plurality, interaction and irreconcilability: there are many different systems of representation for scientific use in understanding the world, none of them complete, and they may be irreconcilable or non-congruent (cf. Longino, Waters, Kellert).

(ScPI 3) Co-existence with the undesirability or impossibility of interaction: there are many different systems of representation for scientific use in understanding the world, all of them (aim to be) complete, and are (presumed to be) irreconcilable or ignoring each other (cf. Kuhn).

\footnotetext{
${ }^{3}$ Also see Van Bouwel (2013) for more details and questions concerning Sandra Mitchell's understanding of scientific pluralism.
} 


\section{b. Analyzing scientific practice.}

An alternative way of analyzing different understandings of scientific plurality, consists in engaging with scientific practice. We can do this in different ways. First, we can analyze the practitioners' understandings of plurality in science by clarifying what the scientists themselves, both implicitly and explicitly, consider as the ideal approach towards the multiplicity of approaches in their field ('schools', theories, models, research programs, ...); is it aiming for substituting the other approaches, advocating a form of coexistence, where one approach supplements other approaches, or do they propose some form of fruitful interaction, (local) integration, a synthesis or a unification of competing approaches? ${ }^{4}$ And, how do they translate that ideal into practice? I have done this exercise for economics (cf. infra, also see Van Bouwel 2004, 2009, discussing, e.g., Davis 2008; Lawson 2003, 2006) and for International Political Economy (cf. Van Bouwel 2011). I will return to my findings in economics in Section 4. As concerns International Political Economy (IPE), I studied the debates triggered by Benjamin Cohen's International Political Economy. An Intellectual History (2008), in which he explicitly raises the question about how to deal with the plurality of research approaches in IPE. Analyzing the contributions to the debate (see, e.g., Phillips and Weaver 2011), I found many scholars outing themselves as pluralists, but defending very different versions of pluralism, all three versions mentioned above (SCPI 1)-(SCPI 3) are present in the debate often without acknowledging themselves the differences among their understandings of pluralism. That is exactly why philosophers of science should interact with these scholars by learning about the scientists' intuitions on dealing with plurality and help to make their accounts more explicit and, consequently, their practice more productive. Thus, one can engage with scientists who are facing the challenge of plurality in their practice and reporting about it, for instance, in psychiatry (see Kendler 2005), International Relations (Sil and Katzenstein 2010) and in heterodox economics (Garnett 2006). Their common question is how pluralism can be 'operationalized'; how can we promote a pluralist mindset leaving behind the impediments instilled in science by the monistic mindset?

Second, case-studies of scientific practice also inform, test and further the philosophical literature discussed above. We can test whether the different understandings of scientific pluralism developed by philosophers hold in scientific practice. This might be done in interaction with the practitioners as the latter might benefit from the philosophical insights to reflect more explicitly on their ways of dealing with plurality.

Third, once the philosophical accounts of scientific pluralism are refined and made more explicit through interaction with scientific practice, they can be fed back into scientific practice; translating the philosophical explication into practice. The urgency of an apt understanding and the implementation of scientific pluralism in practice, for example, is very sensibly considered and addressed by the psychiatrist Kenneth Kendler (2005), also drawing on the philosophical work of Sandra Mitchell (2002). Another example of this kind of feedback will be discussed below, in Section 4.

\footnotetext{
${ }^{4}$ I will not go into the variety of interpretations among practicing scientists of notions like interaction, integration, unification, synthesis, eclecticism, etc. One can intuitively see that they cover a continuum starting with substitution - where one approach replaces all of his competitors - continuing with different degrees of interaction and integration, and, ending with unification - where all competing approaches are merged into one.
} 


\section{c. Using democratic theory and models of democracy.}

In this paper, I want to present and explore a third fruitful way of making scientific pluralism more explicit, namely by elucidating how different versions of scientific pluralism incarnate different models of democracy. When talking about models of democracy, I think of deliberative democracy, aggregative democracy, participatory democracy, agonistic pluralism, and so on. Drawing on the parallels between models of science and models of democracy we can articulate the different philosophical views on how the multiplicity of research approaches in science (should) interact within a democratic framework and analyze which version of scientific pluralism is epistemically the most productive (in which context). Engaging models of democracy will advance the current philosophy of science literature by being more specific on the exact structure of interaction between different scientific research approaches (e.g. aggregation or deliberation), about which approaches can participate (the conditions for inclusion and exclusion) and on how to deal with bias, value and interest pluralism.

In the philosophy of science literature on scientific pluralism, one can find references to democracy, for instance, also in the debate between Kitcher and Longino (discussed above). But these references to democracy are mostly intuitive and vague without clearly specifying which of the many models of democracy is meant, without paying attention to the many varieties and sophisticated discussions within democratic theory, and without systematically applying models of democracy to problems in philosophy of science. One might wonder whether the ultimate aims of science (e.g., Truth, empirical adequacy, understanding, social and/or economic usefulness) are not too different from the ultimate aims of democracy (e.g., justice, equality, freedom) for the analogy to be fruitful. Should we not first develop an argument in abstracto to legitimize the use of models of democracy in discussing science and the interaction among scientific research approaches? That is what I would call a top-down approach, but I think that is not the only approach possible. The approach I am advocating here is a bottom-up approach. I want to start in medias res, with concrete instances in science, zooming in on the parallels between the social-epistemic interaction among competing research approaches and the collective decision-making processes in democracy; the debates about the structure of interaction, the debates about who can(not) participate and how to deal with the diversity among participants (qua values, interests, biases, ...). As mentioned above, one finds scattered remarks about analogies between science and democracy in the philosophy of science literature that deserve a more systematic study. The epistemic aspects of democracy have also received attention from political scientists (e.g. Estlund 2008). These two elements point at the relations between democracy and epistemology, and by starting from concrete instances of parallels, by undertaking case-studies, we want to clarify the democratic aspects of epistemology, looking for best practices that can be clarified in terms of models of democracy, and scrutinize which epistemic aim(s) they might serve and how they might optimize the social-epistemic processes in science. This might ultimately lead to findings about the relations between the ultimate aims in science and the ultimate aims in democracy, but let us work bottom-up, with one step at a time. Doing so, I will start with presenting one example of how to use democratic theory (in Section 3 ) and explicate the added value of using democratic theory (in Section 4). 


\section{How to use democratic theory: an example.}

Let us elaborate an example to make the third approach discussed in Section $2 \mathrm{c}$ more vivid. In order to so, I introduce one model of democracy, agonistic pluralism, and use it to address the debate on scientific pluralism. It should be emphasized that agonistic pluralism is just one of the models of democracy that can be used in fruitfully addressing philosophy of science problems; I do neither assume that it is the only or best model to address philosophy of science problems, nor that it is the politically the most desirable! We are interested here in its fruitfulness to help us explicating scientific pluralism. ${ }^{5}$

Agonistic pluralism, as elaborated by Chantal Mouffe, criticizes both the deliberative model and the aggregative model of democracy: "When liberals intend to speak about politics, they either think in terms of economics -and that would definitely be the aggregative model- or in terms of morality, and this represents the deliberative model. But what is specific to the political always eludes liberal thought." (Mouffe 2005a: 12) Put briefly, agonistic pluralism emphasizes that the dimension of power is ineradicable in democracy, questions the ideal of consensus, puts contestation and antagonism central and values pluralism positively, cf. "the type of pluralism that I am advocating gives a positive status to differences and questions the objective of unanimity and homogeneity, which is always revealed as fictitious and based on acts of exclusion." (Mouffe 2000a: 19)

I want to focus on two aspects of Mouffe's criticism on the deliberative model of democracy here. First, according to her the consensus cherished by the deliberative model of democracy is de facto not inclusive but oppressive. Following the Habermasian ideal of deliberation it is necessary that the collective decisionmaking processes are so organized that the results are equally in the interest of all, representing an impartial standpoint (cf. Benhabib 1996: 69). But agonistic pluralists claim that the consensus-seeking decision-making (in the common interest of all) conceals informal oppression under the guise of concern for all by disallowing dissent. ${ }^{6}$ Or, as Iris Young puts it: "When discussion participants aim at unity, the appeal to a common good in which they are all supposed to leave behind their particular experience and interests, the perspectives of the privileged are likely to dominate the definition of that common good." (Young 1996: 126) Deliberative theorists postulate the availability of a consensus without exclusion (in the

\footnotetext{
${ }^{5}$ The question that brought me to use the agonistic model of democracy was how to make Helen Longino's norms for critical interaction among approaches more explicit. Longino's account is often considered to be an example of an Habermasian, deliberative account, but I disagree and want to highlight the agonistic elements in it. As I will elaborate in what follows, the agonistic model is mainly criticizing the deliberative model of democracy for being too consensual and neglecting the political. The aggregative model of democracy makes similar mistakes, according to the agonists, and can be classified as (too) consensual pluralism too. The fourth model mentioned above in Section 2c, the participatory model of democracy, will not be discussed in this paper, but one version of scientific pluralism that probably could be characterized as a participatory model is Alison Wylie's (2013) dynamic pluralism.

${ }^{6}$ Rawls and Habermas present their model of democracy as the one that would be chosen by every rational and moral individual in idealized conditions. In that sense there is no place for dissent or disagreement - the one that disagrees is irrational or immoral; the political has been eliminated, according to Mouffe (2005a: 121-22). "Conflicts of interests about economic and social issues - if they still arise - are resolved smoothly through discussions within the framework of public reason, by invoking the principles of justice that everybody endorses. If an unreasonable or irrational person happens to disagree with that state of affairs and intends to disrupt that nice consensus, she or he must be forced, through coercion, to submit to the principles of justice. Such a coercion, however, has nothing to do with oppression, since it is justified by the exercise of reason." (Mouffe 2000a: 29-30)
} 
interest of all) according to Mouffe - an important point we will return to in relation to scientific pluralism below.

Second, the theory of deliberative democracy eliminates conflict and fails to keep contestation alive. Agonistic pluralism points out that the theory of deliberative democracy can accommodate pluralism only by a strategy of depoliticization. This impedes us from acknowledging the nature of the political struggle the political - according to Mouffe; it is the end of politics. ${ }^{7}$ We have to acknowledge power, according to Mouffe, instead of ideally eliminating power and conflict: "In a democratic polity, conflicts and confrontations, far from being signs of imperfection, are the guarantee that democracy is alive and inhabited by pluralism. (...) This is why its survival depends on the possibility of forming collective political identities around clearly differentiated positions and the choice among real alternatives." (Mouffe 2000c: 4) Political contestation should be a continuous practice, avoiding the oppressive consensus (seemingly in the interest of all) and acknowledging the plurality of values and interests (valued positively). On the basis of her critique of deliberative democracy, promoting a form of consensual pluralism, Mouffe develops her alternative, namely agonistic pluralism. Some of the differences with consensual pluralism are enlisted here:

\section{Consensual pluralism}

Eliminates conflict

Consensus without exclusion

Diversity without dissent

Different views are complements

\section{Agonistic/Antagonistic pluralism}

\section{Keep disagreement alive}

No consensus without exclusion

Diversity and dissent

Different views can be substitutes

Thus, Chantal Mouffe's version of agonistic pluralism takes social life to be inherently antagonistic without the possibility for any final reconciliation. She suggests that rather than seeking an impossible consensus, a democracy should enable and institutionalize a plurality of antagonistic positions, in order to create agonistic relations. Agonistic relations differ from antagonistic relations to the extent that antagonism denies every possibility of a (stable or shaky) consensus between the plurality of positions; the "other" is seen as an enemy to be destroyed. Antagonists are not after finding common ground, but to conquer more ground, to annex or colonize. Every party wants - in the end - to get rid of pluralism and install its own regime. Contrary to these antagonists, agonistic pluralists do cherish some form of common ground, a conflictual consensus in Mouffe's terminology, a shared symbolic space. In this sense, agonists "domesticate" antagonism, so that opposing positions confront one another as adversaries who respect their right to differ, rather than enemies who seek to obliterate one another.

\footnotetext{
7 “This struggle among adversaries, which I have referred to as 'agonistic', is what democratic politics is really about and one should never try to put an end to the agonistic confrontation. Now, as we have seen, this is precisely what Rawls is attempting when he declares that one needs to go beyond a constitutional consensus because in such a consensus disagreement still exists concerning the status and content of the basic political rights and liberties and that this creates insecurity and hostility in public life. In fact, what his approach aims at erasing is the very place of the 'adversary'. This is why, if it was ever realized, his ideal democratic society would be one where the agonistic struggle has come to an end." (Mouffe 2005b: 228)
} 


\section{Agonistic pluralism}

Adversaries

Common symbolic space

Interaction/confrontation

Boundaries necessary but not reified

Never-ending debate

\section{Antagonistic pluralism}

\section{Enemies}

No common symbolic space

Incommensurability

Reified boundaries

No debate

Furthermore, Mouffe points at the relation between antagonism and the consensual deliberative theorists; citizens that do not have the possibility of choosing among real alternatives within a democratic system (which is the case when it is too consensual, according to Mouffe), turn to right-wing populists in their dissatisfaction - populists that exploit this dissatisfaction and present themselves as the only alternative to the establishment. The antagonistic relation, as analyzed by Mouffe, is one between outsiders and the establishment, the insiders, presented as one homogeneous group. Whether these inimical relations are mainly the effect of the insiders actually grouping together excluding outsiders, or the outsiders presenting the insiders as grouping together in order to get bigger themselves, is not always clear. According to Mouffe, it seems that the insiders are to 'blame'; she has argued that "the growth of right-wing populist parties in many European countries should be seen as the result of the type of 'politics at the centre' which has become predominant in recent years. With the blurring of the frontiers between left and right, conflicts cannot be expressed any more through the traditional democratic channels hitherto provided by party politics." (Mouffe 2005b: 228)

In order to further clarify the different models of democracy, as presented by Mouffe, we illustrate how they result in different political party constellations. An agonistic democracy sees a confrontation among (clearly differentiated) adversaries, for instance among a liberal-conservative, social-democratic, neoliberal and radical-democratic party. The antagonistic democracy sees a struggle between enemies who do not have any shared principles, for instance, between populist right-wing/anti-Establishment parties and the 'consensus at the centre', e.g., the Third Way politics. The consensual democracy sees a consensus at the centre, for instance, the Third Way as consensus, attempting to transcend the left/right opposition, both old-style social democracy and neo-liberalism. According to Mouffe, this consensual democracy will eventually result in the same constellation as the antagonistic democracy, given that the lack of real alternatives will engender dissatisfaction exploited by right-wing populism and antiestablishment parties.

In conclusion, agonistic pluralists aim at avoiding the antagonistic constellation, looking for ways to transform antagonism into agonism. The political system should provide a framework that deals with conflicts through an agonistic confrontation among adversaries rather than an antagonistic struggle between enemies (cf. Mouffe 2000a: 117). The agonistic confrontation will then keep democratic contestation alive (contra consensual deliberative theorists), without jeopardizing democracy (contra antagonism). 
Now, if we compare the three versions of scientific pluralism distinguished in Section 2a with the different understandings of pluralism in democratic theory as identified by Chantal Mouffe, we notice a lot of overlap and interesting symmetries (which will be further explored in the next Section):

(ScPI 1) Plurality and (local) integration/synthesis: there are many different systems of representation for scientific use in understanding the world, none of them complete, and jointly consistent $=$ Mouffe's consensual pluralism.

(ScPI 2) Plurality, interaction and irreconcilability: there are many different systems of representation for scientific use in understanding the world, none of them complete, and they may be irreconcilable or non-congruent = Mouffe's agonistic pluralism.

(ScPI 3) Co-existence with the undesirability or impossibility of interaction: there are many different systems of representation for scientific use in understanding the world, all of them (aim to be) complete, and (presumed to be) irreconcilable or ignoring each other $=$ Mouffe's antagonistic pluralism.

\section{The fruitfulness of using democratic theory.}

\section{a. In relation to the philosophy of science literature.}

Pointing at the symmetries between the three versions of democracy and the three versions of scientific pluralism does teach us more about, among other things, the desired structures of interaction between different scientific research approaches underlying the different versions of scientific pluralism (consensual pluralism, agonism or antagonism, resulting in consensus or continuing dissent), about who participates (who's included and who's excluded) and to what extent diversity and plurality (of bias, values and interests) are valued. I make some of the epistemic lessons that can be learned from the symmetries more explicit in what follows. For each of the three versions of pluralism identified above, I discuss their position toward dissent, diversity of perspectives and (non-)mainstream approaches. Given that I have presented agonistic pluralism in a very concise way in Section 3 , I will have to present the lessons learned in a very general way too. Obviously this could be done much more detailed, but for now the main point is to show the innovations and novel perspectives that involving democratic theory can engender for the scientific pluralism debate, for our understanding of how different research approaches or knowledge systems should interact. 


\section{Different approaches toward dissent.}

(ScPI 1) Consensual pluralism does presume reconcilability of the research approaches and the possibility of integration. Dissent can only be understood as a temporary state to be solved. Thus, dissent is negatively valued, cf. Sandra Mitchell: "Different levels of analysis might target different partial causes, but will there be no competition between levels? (...) Answers to questions posed at the different levels of analysis cannot be satisfactorily answered without consideration of the other levels." (Mitchell and Dietrich 2006: S77) "The "levels of analysis" framework describes the territory of pluralistic investigations, but it is only by integration of the multiple levels and multiple causes, including attention to the diverse contexts in which they occur, that satisfactory explanations can be generated." (Mitchell and Dietrich 2006: S78) Hence, integration does seem the sine qua non for satisfactory explanations here. This clearly differs from agonistic pluralism in which neither (monistic/non-monistic) metaphysical nor explanatory prejudices are cherished which could exclude - or oblige us to integrate - some adversaries or contenders a priori.

(SCPI 2) Agonistic pluralism has a positive and engaging approach towards (continuing) dissent; it does consider the possibility that the plurality of approaches cannot be integrated, or that the different approaches are not always consistent or reconcilable. Moreover, the interaction of the plurality of approaches (the more developed and evaluated the better) in a never-ending debate among clearly differentiated adversaries, generates better results. If we consider, for instance, explanatory practice, the agonist does not share Mitchell's belief that explanatory integration is necessary in order for the explanation to be satisfactory. Moreover, not every integrative explanation is superior to non-integrative ones (cf. Van Bouwel 2014). In that sense, agonists reject the explanatory integration imperative and consider an explanatory practice in which a plurality of approaches can be considered to provide the best (integrative or non-integrative) explanation as superior.

(ScPl 3) Antagonistic pluralism lacks engagement and positive interaction, so there is no positive dissent, no critical debate, only indifference or a strong inimical opposition between contenders or enemies. The possibility of having a common, shared framework - for instance, on understanding explanatory practice and plurality - in which dissent could be made fruitful is excluded.

\section{Valuing the diversity of perspectives?}

(ScPI 1) By denying the possibility of irreconcilability of approaches, consensual pluralism does minimize or overlook important differences among approaches. Consensualists treat differences as something to be eliminated (in an integrative account), not as a resource for better knowledge production. Furthermore, the plurality of diverse biases is not dealt with; it is overlooked or neutralized as the political (in Mouffe's terminology) eludes consensual pluralism. ${ }^{8}$

\footnotetext{
${ }^{8}$ To make it more concrete, we could use once again Mitchell's plea for integrative pluralism as an example. As quoted above, according to Mitchell, "there is only one causal history" (Mitchell 2002: 66). That is an ontological
} 
(ScPI 2) Agonistic pluralism pays attention to the adversaries' differences and diversity; clearly differentiated adversaries are to be preferred. However, the boundaries between these adversaries are not reified, contrary to antagonistic pluralism.

(ScPl 3) Antagonistic pluralism caricaturizes the enemy and excludes; it is interested in showing that one's own account is complete or comprehensive, and/or reckons that it cannot gain or profit from a conversation or interaction with - let alone an inclusion of - different accounts. Contrary to agonistic pluralism, there is no common ground, no common symbolic space.

\section{Questioning (or not) the mainstream?}

(ScPI 1) Consensual pluralism risks overestimating the importance of mainstream approaches and neglecting 'outsiders' (heterodox approaches) or minimize important differences with outsiders in order to succeed in integrating the plurality of approaches - an integration that is presumed to be always possible (cf. Mouffe's critique on postulating the availability of a consensus without exclusion). In that sense, consensual pluralism tends to be too mainstream.

(ScPI 2) Agonistic pluralism does approach mainstream and non-mainstream approaches on equal footing; it neither overestimates the explanatory importance of scientific approaches in the mainstream, nor dismisses approaches outside the mainstream too easily; the competing approaches are adversaries respecting each other in their rights to differ.

(ScPl 3) Antagonistic pluralism is either completely in favor or radically against the mainstream. Debates between the mainstream and non-mainstream proceed in all-or-nothing-terms. The 'outsiders' might only be instrumental in supporting one's own (presumed) scientificness by pointing at the unscientificness of the outsiders, turning the latter into so-called 'constitutive outsiders' (in Mouffe's terminology).

\section{b. in relation to scientific practice.}

In an earlier paper (Van Bouwel 2009), I analyzed how Chantal Mouffe's democratic theory can help us clarifying the different versions of scientific pluralism (implicitly or explicitly) supported by practitioners in economics as well as the methodological norms that (should) guide the interaction between different approaches in economics. I scrutinized the debate between the orthodoxy and the traditional heterodoxy, categorizing different approaches in contemporary economics following Davis (2008):

claim. A corresponding epistemological claim, boiling down to there being one precise description of the complex of contributing causes, seems to be just an article of faith, a postulation, as well as a premature elimination of plurality. 
- Orthodoxy-neoclassical economics

- New mainstream heterodoxy - behavioral, experimental, evolutionary economics, neuroeconomics, evolutionary game theory, agent-based complexity economics

- Traditional heterodoxy - (old) institutional economics, Marxist economics (and radical economics), post-Keynesian economics, neo-Ricardian economics, social economics and socio-economics, Austrian economics, feminist economics, critical realism, and post-modernist economics

The approach to dissent, the valuing of differences and diversity, and ideas about interaction between the mainstream and non-mainstream (cf. lessons learned above in Section 4a) of these competing approaches in economics were studied. We cannot go into the details here, but looking through "the glasses of democratic theory" unearthed many revealed presuppositions. In general, one could conclude that the orthodoxy in economics seems to understand itself (and its own diversity and plurality) as the integrating consensus theory subscribing to the ( $S C P I$ 1)-version of scientific pluralism. Many of the traditional heterodox voices seem to imitate the orthodoxy in their ideas of integration and advocate the (SCPI 1)-version of scientific pluralism, aiming for a heterodox integration. On the other hand, some of the self-declared pluralists of the traditional heterodoxy seem to consider such a heterodox integration as the new dominant approach to substitute its enemy, the orthodoxy (the orthodoxy might then just be reduced to play the role of the constitutive outsider, a role now played by the heterodoxy); in that sense, they support the (SCPI 3)-version of scientific pluralism. (As mentioned above, Mouffe has been pointing at the relation between antagonism and the consensual pluralism; they might be two sides of the same coin.)

However, in the debate between the heterodoxy and orthodoxy, there are also glimpses of the (ScPI 2)version of scientific pluralism, be it that the terminology is missing to be explicit about it (the same holds for similar debates in International Political Economy, cf. Van Bouwel 2011). Here, the introduction of democratic theory as done in Section 3 might play an important role in clarifying the exact understanding of scientific pluralism.

Besides clarifying the ideas scientists themselves have about scientific pluralism, the three versions of scientific pluralism explicated via models of democracy might also be tested by and improve scientific practice. That would be an example of how refined philosophical accounts can be fed back into scientific practice (cf. above, Section 2b). Consider, for instance, the interaction between the orthodoxy and the traditional heterodoxy in economics. The (lack of) interaction between both has not been very fruitful the last decades (cf. Van Bouwel 2004; Davis 2008). Nowadays, on the other hand, the orthodoxy or mainstream in economics is in a process of transformation driven by the emergence of a collection of new research programs, that were labeled new mainstream heterodoxy above. This new heterodoxy departs from standard neoclassical economics, yet there is a more productive interaction between this new mainstream heterodoxy and the orthodoxy: "This development might be taken as evidence that economics is becoming more pluralistic" (Davis, 2008: 349-50) But what does pluralistic mean here? 
While the understandings of scientific pluralism in the debate between orthodoxy and the traditional heterodoxy were mainly of the first version (ScPI 1) or the third version (ScPI 3) of scientific pluralism, the new mainstream heterodoxy might differ from the traditional heterodoxy in its interaction with the mainstream and its underlying understanding of pluralism, i.e. closer to the second version ( $S c P I$ 2) of scientific pluralism. Take, for instance, behavioral economics, one of the approaches belonging to the new mainstream heterodoxy. According to John Davis (2008), behavioral economics, contrary to the traditional heterodoxy, is more oriented towards interaction with the core of the discipline rather than towards the boundaries, but still keeping distance from integration, maintaining fundamental assumptions at odds with neoclassical orthodoxy. Thus, it seems that behavioral economics could be a case to study the agonistic alternative in more detail as well as its superiority to the antagonism of the traditional heterodoxy's approach. As such behavioral economics could be a test case and help us evaluating the different versions of pluralism on the basis of scientific practice.

\section{Wider applications: Scientific objectivity.}

The example of scientific pluralism developed above is meant to be just one example of how fruitful the application of democratic theory to philosophy of science problems in general might be. There are other problems which could benefit from drawing on the parallels between models of science and models of democracy. In this Section - where the paper turns more programmatic - I want to sketch the possibilities of enriching the debate on scientific objectivity by using democratic theory.

Scientific objectivity has often been associated with impartiality, value-freedom and/or aperspectivality. However, more and more philosophers are questioning these ideas attached to scientific objectivity and start asking empirical questions about the epistemic processes constituting scientific objectivity. They do "not associate objectivity with a transcendental 'view from nowhere', but rather asks empirical questions about the conditions for objective judgment that cannot be separated from the material and social contexts in which epistemic practices occur." (Kukla 2008: 286)

This kind of approach is becoming more widely used for analyzing scientific objectivity in its many historical (e.g., Daston and Galison 1992, 2007; Porter 1996) and contemporary outfits (e.g., Megill 1994; Lloyd 1995; Janack 2002; Douglas 2004, 2009). Scientific objectivity in its material and social contexts turns out - not surprisingly - to be somewhat more complex than the association with impartiality, valuefreedom and/or aperspectivality suggests. Heather Douglas (2009), for instance, identifies seven normatively acceptable but different bases for objectivity, conceptually distinct and irreducible to each other, linked to three different kinds of epistemic processes: (a) human interactions with the world, where we find (1) manipulable and (2) convergent objectivity; (b) individual thought processes with (3) detached and (4) value-neutral objectivity, and, (c) social processes with (5) procedural, (6) concordant and (7) interactive objectivity. 
Here as well, the introduction of models of democracy could advance the discussion on objectivity significantly. Let me give a small example. When we say that an observation is objective if some set of competent observers all concur on a particular observation, we are using objectivity in the sense of concordant objectivity. There are no strict procedural constraints here (contrary to procedural objectivity), no discussion, no interactive discourse that might bring about agreement, just an aggregation of judgments. Interactive objectivity, on the other hand, requires interaction and sees the open community of discussion as crucial for science; the assumption is that by keeping scientific discourse open to scrutiny, the most idiosyncratic biases and blinders can be eliminated and an objective result reached. Bringing in models of democracy, we perceive strong affinities between concordant objectivity and aggregative models of democracy, while interactive objectivity resembles deliberative models.

These affinities between bases for objectivity and models of democracy, suggest that the use of models of democracy can help us tackling the central problems in elaborating a philosophical account of objectivity as a social process: (a) the bias problem (how to deal with bias and the differences qua values and interests of the participants in the scientific discussion); (b) the participation problem (where and how to set up a boundary between those research approaches, scientists and non-scientists that can participate in the discussion and those that cannot); and, (c) the structure of interaction problem (how to organize the interactions and discussions). The answers to these problems remain too vague in the current literature.

Consider, for instance, the interesting critique of Miriam Solomon (2006) - a defender of a form of concordant objectivity - on Helen Longino's interactive objectivity. Solomon argues that the aggregation of individual decisions leads to more objective results than the rational (consensual) deliberations between individuals defended by Longino's Critical Contextual Empiricism-norms (cf. Longino 1990, 2002). The debate between them would gain enormously from introducing models of democracy. It would not only oblige defenders of concordant objectivity to be more specific on the models of aggregation they favour (ways of aggregating, who participates, what's the place of dissent, ...); it would also show what a variety of deliberative models (who participates, consensual and non-consensual outcomes, cf. Mansbridge et al. 2010) has been developed. Considering the deliberative model as monolithic implies missing a lot of different possibilities of epistemic interaction.

Furthermore, Longino's CCE-norms would benefit from an explication in terms of models of democracy. For instance, the third CCE-norm, 3. public standards, seems to be an excellent candidate (the other CCE-norms are: 1. venues for criticism, 2. uptake of criticism, and 4. tempered equality of intellectual authority). This third norm can be read as defining the (changeable!) rules/standards of the game and as stipulating some form of meta-consensus about how the plurality of research approaches should interact. Some scholars have been exploring the idea of codifying a general set of shared standards to enable intercommunity criticism; the idea of a stable common ground in line with consensual pluralism (e.g., Büter 2010). A meta-consensus about pluralism could also be thought of in an Habermasian way (cf. Dryzek 
and Niemeyer 2006). However, it seems unlikely that Longino would opt for cementing a common ground that consolidates the standards and values of the dominant mainstream (that would conflict with the fourth CCE-norm). Furthermore, she also emphasizes the dynamic character of the public standards: "Finally, standards are not a static set but may themselves be criticized and transformed (...)." (Longino 2002: 131).

Longino's idea of public standards might actually be closer to Mouffe's idea of the conflictual consensus than to the Habermasian idea. The conflictual consensus differs from the latter approach of the metaconsensus, as it is not static; the emphasis is put on the shakiness, temporality and precariousness of this common ground, endorsing contestability and pointing out that a stable consensus on pluralism eventually denies pluralism. It is within the conflictual consensus that the confrontation among clearly differentiated adversaries, not enemies, takes place - an adversary being "a legitimate enemy, an enemy with whom we have in common a shared adhesion to the ethico-political principles of democracy." (Mouffe 1999:755) However, there is dissent about the interpretation, the meaning and implementation of these ethicopolitical values and principles, one that could not be resolved through deliberation and rational discussion. That is the antagonistic element in consensus. I will not go deeper into whether Longino's third norm should be interpreted as closer to the Habermasian account or closer to Mouffe's, the point I want to make is that exploring the symmetries between the discussion on Longino's third norm and the discussions on the meta-consensus about pluralism in democratic theory will help us in making the abstract norms of Longino's Critical Contextual Empiricism more concrete as well as clarifying the social-epistemic interaction required.

Thus, turning towards models of democracy will enable us to explicate and improve influential social accounts of scientific objectivity, to overcome many deficiencies of the current literature and to open up new horizons for understanding and optimizing the social-epistemic processes constituting scientific objectivity. Finally, the perceived tension between scientific pluralism and scientific objectivity could be resolved once our understanding of both is founded on models of democracy, and simultaneously optimize the social epistemic processes dealing with plurality leading up to the highest degree of objectivity possible. $^{9}$

\footnotetext{
${ }^{9}$ I have also explored the problem of scientific consensus in this way, see Van Bouwel 2009. Also see Beatty and Moore (2010), a paper that implicitly supports my claim that using up-to-date democratic theory can contribute a lot to further our understanding of issues in philosophy of science.
} 


\section{Conclusion.}

Matching up current pluralist ideas of science and current pluralist ideas of democracy, I have demonstrated how democratic theory can advance our perspectives on science. Both our understanding(s) of scientific pluralism and of scientific objectivity can be spelled more carefully by using models of democracy. Moreover, democratic theory can also help to optimize social-epistemic processes in line with models of democracy. For instance, advocates of consensual pluralism, could learn for the study of actual deliberative-democracy processes, for instance, about how to deal with group polarization in deliberation. Thus, the study of social-political decision-making processes can help to improve the social-epistemic processes. I hope to see more work in this direction in the near future, as it looks really promising with respect to moving our social, interactive epistemology as well as our research practices forward.

Working with democratic models of science is not only relevant for the central discussions in philosophy of science I discussed above. It might, for instance, also contribute to improving the way in which expertise is used in democratic societies. It should, indeed, be questioned whether the current decision procedures involving experts are optimal, cf. the choice of experts, the structure of their interaction and the way in which values and interests are (not) taken into account. (These questions are similar to the ones raised above.) A thorough analysis of plurality, scientific objectivity and consensus-seeking within a democratic framework of intra-scientific interaction (as I advocated in this paper) might teach us relevant lessons on how to deal with scientific plurality at the science-society interface, where scientific plurality also has to be dealt with in addressing societal problems with the help of scientific experts.

Furthermore, paying more attention to plurality - and how to deal with it - helps to adjust our expectations of science. To keep on hoping that scientists can always converge on one theory/model/explanation or one numerical probability and requiring such a convergence, risks undermining any scientific contribution to policy making and society in general. Studying the entwinements of science and democracy, we might eventually come to conclusions about science in line with what Churchill's learned about democracy: "Democracy is the worst form of government, except for all those other forms that have been tried from time to time." (from a House of Commons speech on Nov. 11, 1947)

\section{Acknowledgements.}

The author would like to thank the anonymous reviewers for their helpful comments on earlier versions of this paper. The paper was made possible through the help of Linnea Arvidsson, Lars-Göran Johansson and the Petra och Karl-Erik Hedborgs Stiftelse supporting a research visit at Uppsala University. 


\section{References.}

Beatty, J. and A. Moore (2010) 'Should we Aim for Consensus?' Episteme 7(3): 198-214

Benhabib, S. (1996) 'Toward a Deliberative Model of Democratic Legitimacy?' In: S. Benhabib (ed.). Democracy and Difference: Contesting the Boundaries of the Political. Princeton: Princeton University Press, pp. 67-94.

Büter, A. (2010). 'Social Objectivity and the Problem of Local Epistemologies.' Analyse \& Kritik. 32 (2): 213-230.

Chang, H. (2010) A Case for Pluralism in Science. BSPS Seminar at the LSE, 1 March 2010.

Chang, H. (2012) Is Water $\mathrm{H}_{2} \mathrm{O}$ ? Evidence, Realism and Pluralism. Dordrecht: Springer.

Cohen, B.J. (2008) International Political Economy. An Intellectual History. Princeton: Princeton University Press.

Daston, L. and P. Galison (1992) 'The Image of Objectivity.' Representations 40(1): 81-128.

Daston, L. and P. Galison (2007) Objectivity. Cambridge, MA: Zone Books.

Davis, J. (2008) 'The turn in recent economics and return of orthodoxy.' Cambridge Journal of Economics 32, 349-366.

Douglas, H. (2004) 'The Irreducible Complexity of Objectivity.' Synthese 138(3): 453-473.

Douglas, H. (2009) Science, Policy, and the Value-Free Ideal. Pittsburgh: University of Pittsburgh

Press.

Dryzek, J.S. and S. Niemeyer (2006) 'Reconciling Pluralism and Consensus as Political Ideals.' American Journal of Political Science 50(3), 634-649.

Estlund, D. (2008) Democratic Authority: A Philosophical Framework. Princeton: Princeton University Press.

Freedman, K. (2009) 'Diversity and the Fate of Objectivity.' Social Epistemology 23(1): 45-56.

Garnett, R.F. (2006) 'Paradigms and Pluralism in Heterodox Economics.' Review of Political Economy 18(4):521-546.

Giere, R. (2006) 'Perspectival Pluralism.' In: S. Kellert, H. Longino, and K. Waters (eds.), Scientific Pluralism. Minneapolis: University of Minnesota Press, pp. 26-41.

Harding, S. (1991) Whose Science? Whose Knowledge? Ithaca: Cornell University Press.

Janack, M. (2002) 'Dilemmas of Objectivity.' Social Epistemology 16 (3): 267-281.

Kellert, S., H. Longino, and K. Waters (eds.)(2006) Scientific Pluralism. Minnesota Studies in the Philosophy of Science XIX. Minneapolis: University of Minnesota Press.

Kendler, K. (2005) 'Toward a Philosophical Structure for Psychiatry.' American Journal of Psychiatry 162: 433-440.

Kitcher, Ph. (2001) Science, Truth, and Democracy. New York: Oxford University Press.

Kitcher, Ph. (2002a) 'The Third Way: Reflections on Helen Longino's The Fate of Knowledge.' Philosophy of Science 69: 549-559.

Kitcher, Ph. (2002b) 'Reply to Longino.' Philosophy of Science 69: 569-572

Kukla, R. (2008) 'Naturalizing Objectivity.' Perspectives on Science 16(3): 285-302. 
Kuhn. T. (1962) The Structure of Scientific Revolutions. Chicago: University of Chicago Press.

Lawson, T. (2003) Reorienting Economics. London: Routledge.

Lawson, T. (2006) 'The Nature of Heterodox Economics.' Cambridge Journal of Economics 30, 483-505.

Lloyd, E. (1995) 'Objectivity and the Double Standard for Feminist Epistemologies.' Synthese 104(3):

351-381.

Longino, H. (1990) Science as Social Knowledge. Princeton: Princeton University Press.

Longino, H. (2002a) The Fate of Knowledge. Princeton: Princeton University Press.

Longino, H. (2002b) 'Reply to Philip Kitcher.' Philosophy of Science 69, 573-577.

Longino, H. (2006) 'Theoretical Pluralism and the Scientific Study of Behavior.' In: S. Kellert et al. (eds.), Scientific Pluralism. Minneapolis: University of Minnesota Press, pp. 102-131.

Longino, H. (2013) Studying Human Behavior: How Scientists Investigate Aggression and Sexuality. Chicago: University of Chicago Press.

Mansbridge, J. with J. Bohman, S. Chambers, D. Estlund, A. Føllesdal, A. Fung, C. Lafont, B. Manin, and J. L. Martí (2010) 'The Place of Self-Interest and the Role of Power in Deliberative Democracy.' The Journal of Political Philosophy 18(1): 64-100.

Megill, A. (1994) 'Introduction: Four Senses of Objectivity.' In: A. Megill (ed), Rethinking Objectivity, Durham: Duke University Press, pp. 1-20.

Mitchell, S. (2002) 'Integrative Pluralism.' Biology and Philosophy 17(1), 55-70.

Mitchell, S. (2004) 'Why integrative pluralism?' E :CO 6 (1-2): 81-91.

Mitchell, S. and M. R. Dietrich (2006) 'Integration without Unification: An Argument for Pluralism in the Biological Sciences.' The American Naturalist 168, S73-S79.

Mitchell, S. (2009) Unsimple Truths: Science, Complexity, and Policy. Chicago: University of Chicago Press.

Mouffe, Ch.(1999) 'Deliberative Democracy or Agonistic Pluralism?' Social Research 66, 745-758. Mouffe, Ch. (2000a) The Democratic Paradox. London: Verso.

Mouffe, Ch. (2000b) Deliberative Democracy or Agonistic Pluralism? Reihe Politikwissenschaft. Institut für Höhere Studies, Wien.

Mouffe, Ch. (2000c) Politics and Passions: the Stakes of Democracy (paper). http://www.politeiaconferentie.be/viewpic.php?LAN=N\&TABLE=DOCS\&ID=viewpic.php?LAN=N\&TABLE=DOCS\&ID=124 [retrieved July 3rd 2013].

Mouffe, Ch. (2005a) On the Political. London: Routledge.

Mouffe, Ch. (2005b) 'The limits of John Rawls' pluralism.' Politics, Philosophy \& Economics 4(2), 221-231. Phillips, N. and C. Weaver (2011) International Political Economy. Debating the Past, Present and Future. London: Routledge.

Porter, Th. (1996) Trust in Numbers: The Pursuit of Objectivity in Science and Public Life. Princeton: Princeton University Press.

Ruphy, S. (2011) 'From Hacking's plurality of styles of scientific reasoning to "foliated" pluralism: a philosophically robust form of ontologico-methodological pluralism.' Philosophy of Science 78, (5), 12121222. 
Sil, R. and P. Katzenstein (2010) Beyond Paradigms: Analytic Eclecticism in the Study of World Politics. Basingstoke: Palgrave MacMillan.

Solomon, M. (2006) 'Groupthink' versus The Wisdom of Crowds: The Social Epistemology of Deliberation and Dissent.' The Southern Journal of Philosophy XLIV, Supplement: 28-42.

Van Bouwel, J. (2004) 'Explanatory pluralism in economics: Against the mainstream?' Philosophical Explorations 7(3), 299-315.

Van Bouwel, J. (2009) 'The Problem with(out) Consensus. The Scientific Consensus, Deliberative Democracy and Agonistic Pluralism.' In: J. Van Bouwel (ed.) The Social Sciences and Democracy. Basingstoke: Palgrave Macmillan, pp.121-142.

Van Bouwel, J. (2011) 'Different understandings of scientific pluralism in social science: Inquiring a controversy within International Political Economy.' Paper presented at the 13th Annual Philosophy of Social Science Roundtable in Paris, France (18-20 March 2011).

Van Bouwel, J. (2013) 'Book Review of: Sandra Mitchell (2009). Unsimple Truths. Science, Complexity, and Policy.' Science \& Education 22(2): 411-118.

Van Bouwel, J. (2014) 'Explanatory Strategies beyond the Individualism/Holism Debate.' In: J. Zahle and F. Collin (eds.) Rethinking the Individualism/Holism Debate: Essays in the Philosophy of Social Science. Berlin: Springer.

Van Bouwel, J. and E. Weber (2008) 'A pragmatic defence of non-relativistic explanatory pluralism in history and social science.' History and Theory 47(2), 168-182.

Weber, E. and J. Van Bouwel (2002) 'Can we dispense with the structural explanation of social facts?' Economics and Philosophy 18, 259-275.

Young, I.M. (1996) 'Communication and the Other: Beyond Deliberative Democracy.' In: S. Benhabib (ed.) Democracy and Difference: Contesting the Boundaries of the Political. Princeton: Princeton University Press, pp.120-135.

Wylie, A. (2013) 'A Plurality Of Pluralisms: Collaborative Practice In Archaeology.' Paper presented in her keynote talk at EPSA13, the European Philosophy of Science Association Conference. Helsinki, Finland. 